\title{
Variability of indication criteria in knee and hip replacement: an observational study
}

Raquel Cobos ${ }^{1}$, Amaia Latorre', Felipe Aizpuru ${ }^{1,7,8^{*}}$, Jose I Guenaga ${ }^{2}$, Cristina Sarasqueta ${ }^{3,7}$, Antonio Escobar ${ }^{4,7}$, Lidia García ${ }^{5,7}$, Carmen Herrera-Espiñeira ${ }^{6}$

\begin{abstract}
Background: Total knee (TKR) and hip (THR) replacement (arthroplasty) are effective surgical procedures that relieve pain, improve patients' quality of life and increase functional capacity. Studies on variations in medical practice usually place the indications for performing these procedures to be highly variable, because surgeons appear to follow different criteria when recommending surgery in patients with different severity levels. We therefore proposed a study to evaluate inter-hospital variability in arthroplasty indication.
\end{abstract}

Methods: The pre-surgical condition of 1603 patients included was compared by their personal characteristics, clinical situation and self-perceived health status. Patients were asked to complete two health-related quality of life questionnaires: the generic SF-12 (Short Form) and the specific WOMAC (Western Ontario and Mcmaster Universities) scale. The type of patient undergoing primary arthroplasty was similar in the 15 different hospitals evaluated.

The variability in baseline WOMAC score between hospitals in THR and TKR indication was described by range, mean and standard deviation (SD), mean and standard deviation weighted by the number of procedures at each hospital, high/low ratio or extremal quotient $\left(\mathrm{EQ}_{5-95}\right)$, variation coefficient $\left(\mathrm{CV}_{5-95}\right)$ and weighted variation coefficient $\left(\mathrm{WCV}_{5-95}\right)$ for 5-95 percentile range. The variability in subjective and objective signs was evaluated using median, range and $\mathrm{WCV}_{5-95}$. The appropriateness of the procedures performed was calculated using a specific threshold proposed by Quintana et al for assessing pain and functional capacity.

Results: The variability expressed as $\mathrm{WCV}_{5-95}$ was very low, between 0.05 and 0.11 for all three dimensions on WOMAC scale for both types of procedure in all participating hospitals. The variability in the physical and mental SF-12 components was very low for both types of procedure (0.08 and 0.07 for hip and 0.03 and 0.07 for knee surgery patients). However, a moderate-high variability was detected in subjective-objective signs. Among all the surgeries performed, approximately a quarter of them could be considered to be inappropriate.

Conclusions: A greater inter-hospital variability was observed for objective than for subjective signs for both procedures, suggesting that the differences in clinical criteria followed by surgeons when indicating arthroplasty are the main responsible factors for the variation in surgery rates.

\section{Background}

Total knee replacement (TKR) and total hip replacement (THR) are safe surgical procedures that achieve effective pain reduction and adequate restoration of function in the vast majority of patients suffering from advanced knee, hip and other forms of osteoarthritis $[1,2]$. Furthermore, it is widely accepted that the

\footnotetext{
* Correspondence: felipeesteban.aizpurubarandiaran@osakidetza.net 'Health Research Unit of Alava, Basque Health Service, José Achótegui s/n, 01009, Vitoria-Gasteiz, Álava, Spain

Full list of author information is available at the end of the article
}

functional benefits of these kinds of procedures exceed their clinical risks and costs [3].

The main reason for indicating these procedures is osteoarthritis, which in Spain affects around 10\% of the general population [4]. Several studies have reported that the prevalence of osteoarthritis is high in the over 60 's age group, ranging from $5-7.4 \%$ and $10.2-12.2 \%$ for hip and knee disease, respectively [4,5], although the method used to calculate the prevalence influences these values [6]. According to these authors, the disease is more common in women and tends to increase with

\section{Ciomed Central}


age. Obesity is a risk factor for osteoarthritis, both for onset and progression, especially in the case of knee diseases; the relationship in hip osteoarthritis is much weaker $[7,8]$.

Osteoarthritis is the most common form of arthritis. The condition is characterised by loss or failure of the functional and/or biochemical integrity of the joint. Osteoarthritis symptoms include joint pain, stiffness, and dysfunction, but the principal problem for the majority of patients is the pain [9]. Diseases of the musculoskeletal system have a clearly detrimental effect on health related quality of life $[4,10]$ as they significantly affect basic activities such as climbing up or going down stairs and changing position from sitting to standing, as well as ambulating and mobility in general [11,12].

Tornero et al. reported that osteoarthritis is by far the main cause of rheumatic disease-related temporary and permanent disability and is the second cause of permanent disability after cardiovascular diseases [13]. It is also the main cause of pain and disability in the elderly and the main reason for hip- and knee-joint replacement [14].

In the medical literature reviewed there seems to be a consensus regarding the importance of pain and limited functional capacity when indicating surgical intervention [15-19], although there is some disagreement regarding the importance of other patient characteristics such as obesity, age, comorbidity, employment situation, range of active flexion and extension, pain when walking, feeling of instability, radiographic evidence of moderate or severe osteoarthritis, pain at night, and patient request for treatment, among others [19].

In the last years there has been a notable increase in the number of hip and knee arthroplasties. This increase, together with differences in intervention rates and clinical criteria [20], means that an analysis of the appropriate use of these procedures is required as inappropriate surgery leads to longer waiting lists and unnecessary increases in health expenditure.

Area variation in the rates of knee replacement may occur for many reasons, including differences in disease prevalence or severity, differences in patients' and surgeons' expectations and preferences for treatment, as well as restricted access to procedure. So, geographic variation in the rates not accounted for by disease prevalence or severity may represent underuse of the procedure in some areas, overuse in other areas or a combination of the two [19].

Variations in orthopaedic and musculoskeletal surgery have been reported in different countries such as the United States [21], Canada [22] and Spain, where a study undertaken in 2002 involving 111 health regions from 9 Autonomous Communities reported intervention rates that were five- (hip) and six-times (knee) higher in some centres than others [23]. This variability depends, amongst other factors, on the clinical criteria followed by surgeons in the different regions to prescribe the procedure for cases of different severity, meaning that a percentage of surgeries performed might be considered to be "inappropriate or unfounded" [24].

In order to determine the inter-hospital variability in the baseline WOMAC and clinical situation when indicating TKR or THR, a prospective multicentre study involving 15 Spanish hospitals from the Basque Country, Andalucia and Canary Islands was proposed. As the secondary objective, the number of inappropriate procedures performed was calculated on the basis of the minimal pain and functional capacity threshold proposed by Quintana et al [24].

\section{Methods}

\section{Study design and inclusion/exclusion criteria}

A multicentre prospective observational study in 15 hospitals from the Basque Country, Canary Islands and Andalucia involving patients over 18 years of age, diagnosed with primary knee or hip osteoarthritis who underwent total knee (CIE-9-MC: 8154) or total hip replacement (CIE-9-MC: 8151). Patients were selected from the waiting list databases for these surgical interventions in the participating hospitals between July 2005 and December 2006. Patients who were illiterate or suffering from a neuropsychiatric disorder were excluded.

This study was approved by the Health Human Research Ethics Committee of each participating hospital according to the Declaration of Helsinki. All patients gave informed consent to participate in the study.

\section{Measurements}

In all the participating hospitals, the preoperative situation of patients was assessed on the basis of personal characteristics, clinical situation and self-perceived health status. Two health-related quality of life questionnaires were used: the WOMAC, which is disease specific, and a generic questionnaire (SF-12), both translated into Spanish and validated. The WOMAC questionnaire $[25,26]$ evaluates three dimensions: pain, stiffness and functional capacity. Each dimension contains 5, 2 and 17 items respectively, all of which are scored on a Likert-type scale with 5 options of answer. Questionnaires with one blank item in the pain and stiffness dimensions and between one and three blank items in the functional capacity dimension were corrected according to the procedure proposed by Bellamy et al, with missing data for the unanswered items being replaced by the mean value of items answered for each dimension [27]. Questionnaires with two or more blank items in the pain dimension, two blank items in the stiffness dimension and four or more blank items in the 
functional capacity dimension were not considered in the statistical analysis in this section.

In order to compare the study outcomes with those reported in the literature, the score for each WOMAC dimension was standardized to a scale of 0 to 100 (where 0 represents the best possible health status and 100 the worst).

To assess the study's secondary objective, a procedure was considered to be inappropriate when WOMAC pain or functional capacity dimension scores were 40 or lower [24].

Version 1 of the SF-12 questionnaire [28], a shorter form of the SF-36, was used. This questionnaire includes 12 items that provide two summary scores, one each for the physical (Physical Health Composite Score -PCS-) and mental (Mental Health Composite Score -MCS-) components. These summaries range from 0 to 100 (where 0 represents the worst possible status -physical or mental- and 100 the best).

Both questionnaires were given to patients when they attended the hospital either to be scheduled for surgery or for blood extraction if they were included in a selfblood transfusion programme. They were asked to complete these questionnaires and return them upon admission to hospital.

The number of chronic diseases in addition to osteoarthritis and different subjective and objective signs appropriate to each process were considered to assess the clinical situation upon admission. In knee osteoarthritis, signs measured included pain while walking, pain at rest, ambulating capacity, stair climbing, getting up from a chair, limping, need for walking aids/ wheelchair, muscle strength, active extension, passive extension, passive flexion and instability. For the hip osteoarthritis score, the subjective and objective signs assessed were pain at rest, pain while walking, ambulating capacity, limping, stair climbing, needed for walking aids/wheelchair, range of motion (abduction, adduction, internal rotation, external rotation, flexion and extension), Trendelenburg test and dysmetria. All signs were scored on different scales with between two and five answer options and subsequently grouped into two classes of severity: mild or moderate/severe. The values of these variables after reclassification are listed in Table 1.

\section{Statistical analysis}

The data were analysed using the SPSS (Statistical Package for the Social Sciences) software (Version 16.0).

Sample characteristics were described on the basis of the mean and standard deviation or the percentage distribution and $95 \%$ confidence interval $(95 \% \mathrm{CI})$ depending on the continuous or categorical nature of the variables.
To describe the inter-hospital variability in hip and knee replacement indication, the range, mean and standard deviation (SD), mean and standard deviation weighted for the number of procedures undertaken in each hospital, extremal quotient $\left(\mathrm{EQ}_{5-95}\right)$, coefficient of variation $\left(\mathrm{CV}_{5-95}\right)$ and the weighted coefficient of variation for the 5-95 percentile range $\left(\mathrm{WCV}_{5-95}\right)$ were calculated for pain, stiffness and functional-capacity dimensions on the WOMAC scale and for the physical and mental components of the SF-12 scale. The variability in subjective and objective signs was described by the median, range and $\mathrm{WCV}_{5-95}$.

The variability was considered low for values of $\mathrm{CV}_{5-95}$ or $\mathrm{WCV}_{5-95}$ of up to 0.30 and moderate to high for values of 0.30 or above $[29,30]$.

The odds ratio (OR) was calculated to estimate the risk of undergoing an inappropriate intervention as a function of gender.

\section{Results}

\section{Sample description}

Among the 622 patients underwent THR, 336 were men (54.0\%). Considering both sexes, in THR group, the mean (SD) age was $65.4(12.2)$ years and the mean (SD) body mass index (BMI) was 28.2 (4.1), The mean number of chronic diseases in addition to osteoarthritis upon admission to hospital was 1.1 (1.1). Overall, 160 (47.6\%) men and $88(30.8 \%)$ women underwent THR before 65 years of age $(\mathrm{p}<0.001)$.

Among the 981 patients underwent TKR, 698 were women $(71.2 \%)$. The mean age of all the patients was 70.5 (7.4) and the mean BMI was 30.6 (4.8). The number of chronic diseases in addition to osteoarthritis upon admission to hospital was 1.5 (1.2). Overall, 66 $(23.3 \%)$ men and $124(17.8 \%)$ women underwent TKR before 65 years of age $(\mathrm{p}=0.046)$.

\section{Patient Outcomes}

The weighted mean of the WOMAC score for the THR group was 56.5 (4.9) for pain, 58.9 (6.2) for stiffness and 66.1 (4.2) for functional capacity, and the mean values for the physical and mental components of SF-12 questionnaire were 29.6 (2.6) and 42.7 (3.4) respectively.

The corresponding values for the TKR group were 57.0 (4.0) (pain), 58.7 (6.7) (stiffness) and 63.5 (4.6) (functional capacity) on the WOMAC scale and 29.8 (1.8) (physical component) and 42.2 (2.9) (mental component) on the SF-12.

The inter-hospital variability, expressed as $\mathrm{WCV}_{5-95}$, was very low (0.03-0.11) in all cases (Tables 2 and 3).

\section{Subjective and objective signs of severity}

In THR group, the objective signs with the greatest interhospital variation were "flexion $\leq 60^{\circ}$ " $\left(\mathrm{WCV}_{5-95}=0.62\right)$, 
Table 1 Subjective and objective signs by category

\begin{tabular}{|c|c|c|c|c|}
\hline \multirow[t]{2}{*}{ SIGNS } & \multirow[t]{2}{*}{ JOINT } & \multirow[t]{2}{*}{ VARIABLES } & \multicolumn{2}{|r|}{ STATUS } \\
\hline & & & Mild & Moderate/Severe \\
\hline \multirow[t]{7}{*}{$\begin{array}{l}\text { SUBJECTIVE } \\
\text { SIGNS }\end{array}$} & \multirow[t]{5}{*}{$\begin{array}{l}\text { Knee/ } \\
\text { Hip }\end{array}$} & Pain at rest & $\begin{array}{l}\text { None } \\
\text { Mild/occasional }\end{array}$ & $\begin{array}{l}\text { Moderate } \\
\text { Severe }\end{array}$ \\
\hline & & Pain while walking & $\begin{array}{l}\text { None } \\
\text { Mild/occasional }\end{array}$ & $\begin{array}{l}\text { Moderate } \\
\text { Severe }\end{array}$ \\
\hline & & Ambulating capacity & $\begin{array}{l}\text { More than } 100 \text { meters and more than } 15 \\
\text { minutes }\end{array}$ & $\begin{array}{l}\text { Less than } 100 \text { meters and/or standing for less than } \\
15 \text { minutes. } \\
\text { Cannot walk or stand }\end{array}$ \\
\hline & & Stairs climbing & Normal & With support of the banisters \\
\hline & & Limping & $\begin{array}{l}\text { No limping } \\
\text { Mild limping }\end{array}$ & $\begin{array}{l}\text { Moderate limping } \\
\text { Severe limping } \\
\text { Wheelchair } \\
\text { Confined to bed }\end{array}$ \\
\hline & Knee & Getting up from a chair & Normal & With help \\
\hline & $\begin{array}{l}\text { Knee/ } \\
\text { Hip }\end{array}$ & $\begin{array}{l}\text { Need for walking aids/ } \\
\text { wheelchair }\end{array}$ & $\begin{array}{l}\text { None } \\
\text { Stick or crutches needs just for long } \\
\text { distances }\end{array}$ & $\begin{array}{l}\text { Most of the time, one or two crutches } \\
\text { Zimmer frame } \\
\text { Wheelchair }\end{array}$ \\
\hline \multirow[t]{13}{*}{$\begin{array}{l}\text { OBJECTIVE } \\
\text { SIGNS }\end{array}$} & \multirow[t]{5}{*}{ Knee } & Muscle strength & $\begin{array}{l}\text { Counteracts gravity but does not } \\
\text { counteract resistance } \\
\text { Counteracts gravity and resistance }\end{array}$ & $\begin{array}{l}\text { Slight muscular contraction } \\
\text { Potential muscular contraction but insufficient to } \\
\text { counteract gravity }\end{array}$ \\
\hline & & Active extension & $>5^{\circ}$ & $\leq 5^{\circ}$ \\
\hline & & Degree of instability & $\leq 5^{\circ}$ & $>5^{\circ}$ \\
\hline & & Passive extension & $>10^{\circ}$ & $\leq 10^{\circ}$ \\
\hline & & Passive flexion & $>100^{\circ}$ & $\leq 100^{\circ}$ \\
\hline & \multirow[t]{8}{*}{ Hip } & Flexion & $>60^{\circ}$ & $\leq 60^{\circ}$ \\
\hline & & Abduction & $>10^{\circ}$ & $\leq 10^{\circ}$ \\
\hline & & Adduction & $>10^{\circ}$ & $\leq 10^{\circ}$ \\
\hline & & Extension & $>10^{\circ}$ & $\leq 10^{\circ}$ \\
\hline & & Internal rotation & $>10^{\circ}$ & $\leq 10^{\circ}$ \\
\hline & & External rotation & $>10^{\circ}$ & $\leq 10^{\circ}$ \\
\hline & & Trendelenburg & No & Yes \\
\hline & & Dysmetria & No & Yes \\
\hline
\end{tabular}

"positive Trendelenburg" ( $\left.\mathrm{WCV}_{5-95}=0.76\right)$ and "dysmetria" $\left(\mathrm{WCV}_{5-95}=0.58\right)$, and the subjective signs were "ambulation limited to less than 100 meters and/or 15 minutes" $\left(\mathrm{WCV}_{5-95}=0.50\right)$, "moderate to severe limp" $\left(\mathrm{WCV}_{5-95}=0.34\right)$ and "need for walking aids - one or two crutches most of the time/Zimmer frame - or wheelchair" $\left(\mathrm{WCV}_{5-95}=0.31\right)$. The results of the WOMAC variability by intervention type are reported in Table 4 .

In the TKR group, the inter-hospital variability for objective signs was very high for "instability $>5^{\circ}$ " and "muscle

Table 2 Variability in the WOMAC questionnaire by intervention type

\begin{tabular}{|c|c|c|c|c|c|c|}
\hline \multirow[t]{3}{*}{ VARIABILITY INDICATORS } & \multicolumn{6}{|c|}{ WOMAC QUESTIONNAIRE } \\
\hline & \multicolumn{2}{|l|}{ Pain } & \multicolumn{2}{|l|}{ Stiffness } & \multicolumn{2}{|c|}{ Functional capacity } \\
\hline & Hip & Knee & Hip & Knee & Hip & Knee \\
\hline No. of cases & 622 & 981 & 622 & 981 & 622 & 981 \\
\hline Range & $47.5-68.3$ & $51.7-65.5$ & $45.1-67.2$ & $45.7-67.3$ & $61.1-82.5$ & $53.3-72.5$ \\
\hline Mean (SD) & $57.1(5.7)$ & $57.2(4.3)$ & $59.4(5.3)$ & $59.5(6.5)$ & $67.4(5.9)$ & $63.8(5.3)$ \\
\hline Weighted mean (SD) & $56.5(4.9)$ & $57.0(4.0)$ & $58.9(6.2)$ & $58.7(6.7)$ & $66.1(4.2)$ & $63.5(4.6)$ \\
\hline $\mathrm{EQ}_{5-95}$ & 1.4 & 1.24 & 1.5 & 1.47 & 1.3 & 1.32 \\
\hline $\mathrm{CV}_{5-95}$ & 0.08 & 0.06 & 0.08 & 0.11 & 0.06 & 0.06 \\
\hline WCV $_{5-95}$ & 0.05 & 0.06 & 0.10 & 0.11 & 0.06 & 0.06 \\
\hline
\end{tabular}

SD - Standard deviation.

$\mathrm{EQ}_{5-95}$ - Extremal quotient for the 5-95 percentile range.

$\mathrm{CV}_{5-95}$ - Coefficient of variance for the 5-95 percentile range.

WCV $_{5-95}$ - Weighted coefficient of variance for the 5-95 percentile range. 
Table 3 Variability in the SF-12 questionnaire by intervention type

\begin{tabular}{|c|c|c|c|c|}
\hline \multirow[t]{3}{*}{$\begin{array}{l}\text { VARIABILITY } \\
\text { INDICATORS }\end{array}$} & \multicolumn{4}{|c|}{$\begin{array}{l}\text { SF-12 } \\
\text { QUESTIONNAIRE }\end{array}$} \\
\hline & \multicolumn{2}{|c|}{ Physical component } & \multicolumn{2}{|c|}{ Mental component } \\
\hline & Hip & Knee & Hip & Knee \\
\hline No. of cases & 503 & 815 & 503 & 815 \\
\hline Range & $\begin{array}{l}25.1- \\
36.0\end{array}$ & $\begin{array}{l}25.5- \\
33.8\end{array}$ & $\begin{array}{l}31.5- \\
45.9\end{array}$ & $\begin{array}{l}35.9- \\
49.4\end{array}$ \\
\hline Mean (SD) & $29.7(3.1)$ & $29.5(1.9)$ & $41.9(4.3)$ & $42.0(3.7)$ \\
\hline Weighted mean (SD) & $29.6(2.6)$ & $29.8(1.8)$ & $42.7(3.4)$ & $42.2(2.9)$ \\
\hline $\mathrm{EQ}_{5-95}$ & 1.4 & 1.3 & 1.5 & 1.3 \\
\hline $\mathrm{CV}_{5-95}$ & 0.08 & 0.05 & 0.08 & 0.08 \\
\hline WCV $_{5-95}$ & 0.08 & 0.03 & 0.07 & 0.07 \\
\hline
\end{tabular}

SD - Standard deviation.

$\mathrm{EQ}_{5-95}$ - Extremal quotient for the 5-95 percentile range.

$\mathrm{CV}_{5-95}$ - Coefficient of variance for the 5-95 percentile range.

$W \mathrm{VV}_{5-95}$ - Weighted coefficient of variance for the 5-95 percentile range.

strength - contraction not counteracting gravity" with $\mathrm{WCV}_{5-95}$ values of 0.69 and 0.52 , respectively. The subjective signs with greatest inter-hospital variability were "pain at rest", "ambulation limited to less than 100 meters and/or 15 minutes" and "need for walking aids - one or two crutches most of the time/Zimmer frame - or wheelchair", with $\mathrm{WCV}_{5-95}$ scores of $0.40,0.42$ and 0.52 , respectively.

\section{Inappropriate interventions}

Among all the surgeries performed, 153 hip operations (24.6\%; 95\% CI: $21.2 \%-28.0 \%$ ) and 250 knee operations
(25.5\%; 95\% CI: $22.8 \%-28.2 \%)$ were inappropriate according to the criteria used in this study. The range between hospitals varied between $10 \%$ and $35.7 \%$ for hip operations and between $7.3 \%$ and $41.7 \%$ for knee surgery. Patients who underwent an inappropriate TKR were older (72.0 (6.9) versus $69.9(7.5) ; \mathrm{p}<0.001)$ and more likely to be men $[33.2 \%(\mathrm{n}=94)$ versus $22.3 \%(\mathrm{n}$ = 156), $\mathrm{p}<0.001$; OR 1.7 (95\% CI: 1.3-2.3)] than members of the appropriate surgery group. Among the patients who underwent THR there were no significant differences between groups (appropriate or inappropriate intervention) in terms of age, but the same pattern was observed regarding gender [28.3\% $(\mathrm{n}=95)$ of men' interventions versus $20.3 \%(\mathrm{n}=58)$ of women' interventions were labelled as inappropriate, $\mathrm{p}=0.022$; OR 1.6 (95\% CI: 1.1-2.3)].

Within the appropriate surgery group, men were younger than women for both types of procedures (mean age of men was 68.8 (7.8-standard deviation-) versus 70.3 (7.3) for women, $\mathrm{p}=0.014$ in TKR; and 63.0 (12.9) versus 68.0 (11.3), $\mathrm{p}<0.001$ respectively in THR), while in the inappropriate surgery group there was no significant difference between the mean age of men and women $(\mathrm{p}=0.942$ and $\mathrm{p}=0.183$ in TKR and THR respectively).

\section{Discussion}

This study involved 981 patients who underwent knee arthroplasty and 622, hip arthroplasty. Both groups were

Table 4 Variability in subjective and objective signs by intervention type

\begin{tabular}{|c|c|c|c|c|c|}
\hline \multirow[t]{2}{*}{ SIGNS } & & \multicolumn{2}{|c|}{ HIP } & \multicolumn{2}{|c|}{ KNEE } \\
\hline & & Median (Range) & $W C V_{5-95}$ & Median (Range) & $W C V_{5-9}$ \\
\hline \multirow[t]{7}{*}{ SUBJECTIVE SIGNS } & Pain whilst walking (\%) & $93.2(82.1-100)$ & 0.06 & $94.1(52.9-100)$ & 0.12 \\
\hline & Pain at rest (\%) & $50(7.1-72.7)$ & 0.23 & $43.5(7.7-80.5)$ & 0.40 \\
\hline & Ambulating capacity (\%) & $26.9(0.0-61.8)$ & 0.50 & $27.3(2.1-100)$ & 0.42 \\
\hline & Stair climbing (\%) & $90.9(69.2-100)$ & 0.10 & $95.2(63.8-100)$ & 0.08 \\
\hline & Limping (\%) & $81.8(26.1-100)$ & 0.34 & $68.3(19.1-100)$ & 0.30 \\
\hline & Need for walking aids/wheelchair (\%) & $42.9(10.0-80.0)$ & 0.31 & $36.4(8.3-100)$ & 0.52 \\
\hline & Getting up from a chair (\%) & & & $64.7(18.2-100)$ & 0.23 \\
\hline \multirow[t]{13}{*}{ OBJECTIVE SIGNS } & Abduction $\left(\leq 10^{\circ}\right)(\%)$ & $36.1(0.0-60.0)$ & 0.38 & & \\
\hline & Adduction $\left(\leq 10^{\circ}\right)(\%)$ & $60.0(0.0-100)$ & 0.43 & & \\
\hline & Flexion $\left(\leq 60^{\circ}\right)(\%)$ & $18.2(0.0-75.0)$ & 0.62 & & \\
\hline & Extension $\left(\leq 10^{\circ}\right)(\%)$ & $92.3(36.2-100)$ & 0.08 & & \\
\hline & Internal rotation $\left(\leq 10^{\circ}\right)(\%)$ & $85.7(44.8-100)$ & 0.13 & & \\
\hline & External rotation $\left(\leq 10^{\circ}\right)(\%)$ & $62.5(19.3-92.3)$ & 0.15 & & \\
\hline & Trendelenburg (yes) (\%) & $3.8(0.0-100)$ & 0.76 & & \\
\hline & Dysmetria (yes) (\%) & $33.3(0.0-100)$ & 0.58 & & \\
\hline & Muscle strength (contraction not counteracting gravity) & & & $9.1(0.0-45.5)$ & 0.52 \\
\hline & Active extension $\left(\leq 5^{\circ}\right)(\%)$ & & & $77.2(30.0-100)$ & 0.19 \\
\hline & Passive extension $\left(\leq 10^{\circ}\right)(\%)$ & & & $92.5(50.0-100)$ & 0.11 \\
\hline & Passive flexion $\left(<100^{\circ}\right)(\%)$ & & & $41.7(21.3-100)$ & 0.34 \\
\hline & Instability degree $\left(>5^{\circ}\right)(\%)$ & & & $20.5(0.0-100)$ & 0.69 \\
\hline
\end{tabular}


similar in terms of age and gender distribution to those studied by other authors [24,31,32], with more women in the TKR group and a higher proportion of men undergoing hip surgery. In addition, patients of the TKR were older (70.5 (7.4) years) than those in the THR group (65.4 (12.2)).

Approximately a third of the women and half of the men in the THR group were younger than 65 years of age when they have been operated $(\mathrm{p}<0.001)$. Previous studies $[33,34]$ have suggested that osteoarthritis is more common in women than in men but that women tend to undergo arthroplasty at a more advanced stage of the disease. The mechanisms underlying these gender-related differences are not yet clear but may be related to the patient's level of activity, the duration of their symptoms and their level of disability. A study published by Karlson et al. reported that men had a higher level of activity and carried out heavier works than women. The study also found that men had greater confidence in the surgeon's ability and were less afraid of a negative surgical outcome than women. In contrast, women were more worried than men about being a burden on other people after the surgery and stated three reasons for postponing surgery: 1) they preferred to wait until they reached a certain level of pain or suffered loss of functional capacity or interference with an essential activity; 2) they were waiting for the technology to improve; and 3) the procedure could not be delayed any longer [34].

A similar difference was observed in the TKR group, with around a quarter of men and a fifth of women being operated before 65 years of age $(p=0.161)$.

The mean number of chronic diseases in addition to osteoarthritis upon admission was 1.1 (1.1) for the THR group and 1.5 (1.2) for the TKR group, possibly due to the higher average age of the patients undergoing knee surgery. These values are similar to rates of chronic diseases in the general population in Spain [1.4 for patients between 65 and 69 years of age and 1.6 and for those between 70 and 74 years of age [35]].

In the THR group 449 patients $(80.5 \%)$ and in the TKR group 752 patients $(89.1 \%)$ were overweight or obese $(B M I \geq 25)(p<0.001)$. These values are similar to those reported previously $(8,36)$ and confirm that obesity is a more important risk factor for knee osteoarthritis than for hip osteoarthritis.

The scores obtained on both components of the SF-12 were lower (worse) than those of the general population [28], and similar to results from other researchs on THR and TKR, such as that reported by Hamel et al [37]. In both cases, the variation in osteoarthritis-specific (WOMAC) and in the general (SF-12) questionnaires between the 15 participating hospitals was very small $\left(\mathrm{WCV}_{5-95}\right.$ between 0.03 and 0.11 ).
There is general agreement among physicians that pain should be considered the principal criterion for determining who is a candidate for primary hip or knee arthroplasty $[15,38]$. In line with this, the percentage of patients undergoing THR with severe "pain when walking" was over $90 \%$ in half of the hospitals we studied (82.1\% in the hospital with the lowest rate). In the TKR group, the percentage of patients reporting severe pain when walking before the surgery was also above $90 \%$ in half of the hospitals, but the figure for one of the hospitals was as low as $52.9 \%$. Nevertheless, the overall variability was small (0.06-0.12) in both cases.

In contrast, the percentage of patients with severe "pain at rest" prior to intervention was less than 50\% and $43.5 \%$ for THR and TKR respectively in the half of the hospitals. Moreover, the inter-hospital variability in this case was low $\left(\mathrm{WCV}_{5-95}=0.23\right)$ in the THR group but moderate to high $\left(\mathrm{WCV}_{5-95}=0.40\right)$ in the TKR group. In both cases, there were hospitals with very low percentages of patients $(7.1 \%$; 1 of 14 in hip arthroplasty) and (7.7\%; 1 of 13 in knee arthroplasty), suffering from severe pain at rest. This variability in the objective signs might reflect different cultural perceptions of pain according to geographical origin. It might also suggest the difference among clinicians when assesing pain, since these signs were obtained by physicians upon admission.

Looking at the other subjective signs assessed, except for "the need to hold on to the banister when climbing stairs" in both types of interventions and for "getting up from a chair" in the TKR group, the variability was moderate - for "limping" $\left(\mathrm{WCV}_{5-95}=0.34\right.$ in THR and 0.30 in TKR) and "need for walking aids/wheelchair" in the THR group $\left(\mathrm{WCV}_{5-95}=0.31\right)$, or moderate to severe $\left(\mathrm{WCV}_{5-95} \geq 0.40\right)$ for "limitations in ambulating" in both types of interventions and for "need for walking aids/ wheelchair" in the TKR group. Once again, this variation highlights the fact that physicians follow different clinical criteria when indicating surgery within the same country, i.e., in similar populations suffering from the same diseases.

On the other hand, the large variability observed in the objective signs analysed could be due to inadequate data collection.

In a study published in September 2009, Quintana et al. proposed minimum scores on the WOMAC pain and functional capacity scales above which surgery would be indicated to achieve a clinically relevant improvement of 30 and 25 points on the pain and functional-capacity scales, respectively. This gain was clinically relevant for pre-intervention WOMAC functional limitation domain values $>60$ or between 40 and 60 accompanied by a level of pain $>40$ [15]. If we consider this threshold to be appropriate, only 1200 of the 1603 patients whose 
WOMAC pain and functional-capacity scores were calculated should have undergone surgery $(74.9 \%)$. A breakdown of the number of inappropriate interventions (403; $25.1 \%)$ by hospital and surgery type reveals a variability, expressed as the percentage of patients with a baseline pain or functional capacity score $\leq 40$ points, of $10 \%-35.7 \%$ for the THR group and $7.3 \%-41.7 \%$ for the TKR group. However, the inter-hospital variability $\left(\mathrm{WCV}_{5-95}\right)$ was 0.24 for both surgery groups, which can be considered to be low.

Patients who underwent inappropriate knee surgery were older than those with an appropriate intervention ( $\mathrm{p}$ $<0.001)$. In the appropriate surgery group for both types of procedures, men were younger than women $(\mathrm{p}<0.05)$, but in the inappropriate surgery group, there was no significant difference in the mean age of men and women ( $\mathrm{p}$ $=0.942$ and $p=0.183$ in TKR and THR respectively).

There were more inappropriate interventions among men than women in both types of procedures (OR 1.7 in TKR and 1.6 in THR), meaning that men were operated at lower scores on the WOMAC scale.

Nowadays, it is possible for patients to have higher levels of activity even at older ages and to need surgery earlier in order to maintain an adequate quality of life, especially men with heavy jobs that require an earlier intervention even with lower scores at WOMAC index. However, these hypotheses cannot be answered by the study design.

Since osteoarthritis is one of the most common reasons for primary care consultation in Spain, with a significant socioeconomic cost of around 511 million Euros per year [39], it seems reasonable that clinical and hospital management strategies should adopt criteria for selecting candidates and for reassessing patients on waiting lists. Simply providing more resources to regions with longer waiting lists without monitoring their surgical intervention rates may well be an inappropriate policy because the intervention is likely to be indicated for lower levels of severity [23].

The limitations of this study include the fact that clinical data collection was performed in the hospital activity environment, so the quality of some data might be affected by the typical fluctuations in activity, for example, at peak times. In relation to this, the unequal recruitment rate in the different centres should also be noted. Although we do not believe this have influenced the overall outcomes of the study, it might have affected the accuracy of the estimates in some centres. Further, it was only possible to break the samples down by centre, not by surgeon, although we assume that the criteria followed by different surgeons within the same service tend to be similar.

In relation with the study performed by Quintana et al (which was used as reference because patients' typology was very similar to ours) we assumed that its limitations (an algorithm not externally validated and a high percentage of missing values-approximately a quarter of patients who completed the baseline questionnaires did not respond to the follow-up questionnaires) did not invalidate the conclusions derived from our results. These limitations were not a major problem for authors because, on the one hand, the validity of this algorithm was supported by the similar results obtained by other research groups, and on the other hand, the high percentage of missing values did not result in statistically significant differences in relevant variables when comparing responder patients with no responders.

Finally, the study excludes private hospitals, which might provide a different picture to that obtained from the public sector.

\section{Conclusions}

In conclusion, the type of patient undergoing primary arthroplasty appears to be similar in the different hospitals assessed, although the differences in the clinical criteria followed when indicating surgery mean that approximately a quarter of interventions performed could be considered to be inappropriate. Further research is therefore required to establish guidelines for indicating this type of surgery in order to make better use of existing resources.

\section{Abbreviations}

TKR: (Total Knee Replacement); THR: (Total Hip Replacement); EPISER: (Study on the Prevalence of Rheumatoid Diseases in the Spanish Population); SF: (Short-Form); WOMAC: (Western Ontario and Mcmaster Universities); BMI: (Body Mass Index); SD: (Standard Deviation); 95\% Cl:(Confidence Interval at a 95\% confidence level); EQ: 5-95 (Extremal Quotient for the percentile range 595); CV: $5-95$ (Coefficient of variance for the percentile range 5-95); WCV: 5-95 (Weighted Coefficient of Variance for the percentile range 5-95)

\section{Acknowledgements}

We thank all the participants, whose valuable and helpful contributions and involvement made this study possible.

We are very grateful to funding sources: the Health Research Fund of Spanish Ministry of Health and Consumption (FIS project no 040938) and Health Department of the Government of the Basque Country.

\section{Author details}

${ }^{1}$ Health Research Unit of Alava, Basque Health Service, José Achótegui s/n, 01009, Vitoria-Gasteiz, Álava, Spain. 'Santiago Hospital, Olaguibel, 29, 01004, Vitoria-Gasteiz, Álava, Spain. ${ }^{3}$ Donostia Hospital, Paseo Dr. Beguiristain s/n, 01009, San Sebastian, Guipuzcoa, Spain. ${ }^{4}$ Basurto Hospital, Avda. Montevideo, 18, 48013, Bilbao, Vizcaya, Spain. ${ }^{5}$ Canary Islands Foundation for Health Research (FUNCIS), Pérez de Rozas, 5, $4^{\text {th }}$ Floor, 38004, Santa Cruz de Tenerife, Canary Islands, Spain. ${ }^{6}$ Virgen de las Nieves Hospital, Avda. De Las Fuerzas Armadas, 2, 18014, Granada, Spain. ${ }^{7}$ Network Center for Biomedical Research in Epidemiology and Public Health (CIBERESP), Spain. ${ }^{8}$ University of Basque Country (UPV/EHU), Spain.

\section{Authors' contributions}

$\mathrm{RC}$ was in charge of reviewing the state of the scientific evidence, the draft and revision of the manuscript and the interpretation of the results. $\mathrm{AL}$ completed the statistical analysis and took part in the interpretation of the results. FA was involved in the design of the preliminary study, the revision 
of the manuscript and the interpretation of the results. AE promoted and designed the preliminary study. The remaining co-authors were involved in the recruitment of participants, data collection and quality control. All authors read and approved the final manuscript.

\section{Competing interests}

Raquel Cobos Campos, Amaia Latorre Ramos, Felipe Esteban Aizpuru Barandiaran, Jose Ignacio Guenaga Sustaeta, Cristina Sarasqueta Eizaguirre, Antonio Escobar Martínez, Lidia García Pérez and Carmen Herrera Espiñeira declare that they have no competing interests.

Received: 10 June 2010 Accepted: 26 October 2010

Published: 26 October 2010

\section{References}

1. Forrest G, Fuchs M, Gutierrez A, Giraldy J: Factors affecting length of stay and need for rehabilitation after hip and knee arthroplasty. J Arthroplasty 1998, 13:186-190.

2. Desmeules F, Dionne $C E$, Belzile $E$, Bourbonnais $R$, Frémont P: Waiting for total knee replacement surgery: factors associated with pain, stiffness, function and quality of life. BMC Musculoskelel Disord 2009, 10:52.

3. Navarro JL, Hernández E: Cost-Outcome analysis of joint replacement: evidence from a Spanish public hospital. Gac Sanit 2008, 22:337-343.

4. Carmona L, Ballina J, Gabriel R, Laffon A: The burden of muscoloeskeletal diseases in the general population of Spain: results form a national survey. Ann Rheum Dis 2001, 60:1040-1045.

5. Quintana JM, Arostegui I, Escobar A, Azkarate J, Guenaga Jl, Lafuente I: Prevalence of knee and hip osteoarthritis and the appropriateness of joint replacement in an older population. Arch Intern Med 2008, 168:1576-1584.

6. Peiró S, Librero J, Ridao M, Bernal-Delgado E, Grupo de Variaciones en la Práctica Médica en el Sistema Nacional de Salud: Variabilidad en la utilización de los servicios de urgencias hospitalarios del Sistema Nacional de Salud. Gac Sanit 2010, 24:6-12.

7. Grotle M, Hagen KB, Natvig B, Dahl FA, Kvien TK: Obesity and osteoarthritis in knee, hip and/or hand: an epidemiological study in the general population with 10 years follow-up. BMC Musculoskelet Disord 2008, 9:132.

8. Grazio S, Balen D: Obesity: risk factor and predictor of osteoarthritis. Lijec Vjesn 2009, 131:22-26.

9. Kean WF, Kean R, Buchanan W: Osteoarthritis: symtomps, signs and source of pain. Inflammoharmacology 2004, 12:3-31.

10. Salaffi F, De Angelis R, Stancati A, Grassi W: MArche Pain: Health-related quality of life in multiple musculoskeletal conditions: a cross-sectional population based epidemiological study. II. The MAPPING study. Clin Exp Rheumatol 2005, 23:829-39.

11. Etinger WH, Afable RF: Physical disability from knee osteoarthritis: the role of exercise as an intervention. Med Sci Sports Exerc 1994, 26:1435-1440.

12. Dillon CF, Rasch EK, Gu Q, Hiersch R: Prevalence of knee osteoarthritis in the United States: arthritis data from the Third National Health and Nutrition Examination Survey 1991-94. J Rheumatol 2006, 33:2271-2279.

13. Tornero J, Piqueras JA, Carballo LF, Vidal J: Epidemiología de la discapacidad laboral debida a las enfermedades reumáticas. Rev Esp Reumatol 2002, 29:373-384.

14. Jinks C, Jordan K, Croft P: Measuring the population impact of knee pain and disability with the Western Ontario and McMaster universities osteoarthritis index (WOMAC). Pain 2002, 100:55-64.

15. Mancuso CA, Ranawat CS, Esdaile JM, Johanson NA, Charlson ME: Indications for total hip and total knee arthroplasties. Results of orthopaedic surveys. J Arthroplasty 1996, 11:34-46.

16. Cross WW III, Saleh KJ, Wilt TJ, Kane RL: Agreement about indications for total knee arthroplasty. Clin Orthop Relat Res 2006, 446:34-39.

17. Quintana JM, Bilbao A, Escobar A, Azkarate J, Guenaga Jl: Decision trees for indication of total hip replacement on patients with osteoarthritis. Rheumatology (Oxford) 2009, 48:1402-1409.

18. Dreinhofer KE, Dieppe P, Sturmer T, Grober-Gratz D, Floren M, Gunther KP, Puhl W, Brenner $\mathrm{H}$ : Indications for total hip replacement: comparison of assessments of orthopaedic surgeons and referring physicians. Ann Rheum Dis 2006, 65:1346-1350.

19. Wright JG, Coyte P, Hawker G, Bombardier C, Cooke D, Heck D, Dittus R, Freund D: Variation in orthopedic surgeons' perceptions of the indications for and outcomes of knee replacement. CMAJ 1995, 152:687-697.

20. Escobar A, González N, Quintana JM, Las Hayas C: Priorización de pacientes en lista de espera para prótesis de rodilla y cadera: la opinión de los pacientes. Gac Sanit 2005, 19:379-385.

21. Katz BP, Freund DA, Heck DA, Dittus RS, Paul JE, Wright J, Coyte P, Holleman E, Hawker G: Demographic variation in the rate of knee replacement: a multi-year analysis. Health Serv Res 1996, 31:125-140.

22. Coyte $P C$, Hawker G, Wright JG: Variations in knee replacement utilization rates and the supply of health professionals in Ontario, Canada. J Rheumatol 1996, 23:1214-1220.

23. Grupo Atlas-VPM: Variaciones en cirugía ortopédica y traumatológica. Fractura de cadera, artroplastia de rodilla y artroplastia de cadera. Atlas Var Pract Med SNS 2005, 1:17-36.

24. Quintana JM, Escobar A, Arostegui I, Bilbao A, Azkarate J, Guenaga JI, Arenaza FC: Health-related quality of life and appropriateness of knee or hip joint replacement. Arch Intern Med 2006, 166:220-226.

25. Batlle-Gualda E, Esteve-Vives J, Piera MC, Hargreaves R, Cutts J: Adaptación transcultural del cuestionario WOMAC específico para artrosis de rodilla y cadera. Rev Esp Reumatol 1999, 26:38-45.

26. Escobar A, Quintana JM, Bilbao A, Azkarate J, Güenaga Jl: Validation of the Spanish Version of the WOMAC Questionnaire for Patients with Hip or Knee Osteoarthritis. Clin Rheumatol 2002, 21:466-471.

27. Bellamy N, Buchanan WW, Goldsmith CH, Campbell J, Stitt LW: Validation study of WOMAC: a health status instrument for measuring clinically important patient relevant outcomes to antirheumatic drug therapy in patients with osteoarthritis of the hip or knee. J Rheumatol 1988, 15:1833-1840.

28. Ware J Jr, Kosinski M, Keller SD: A 12-Item Short-Form Health Survey: construction of scales and preliminary tests of reliability and validity. Med Care 1996, 34:220-233.

29. Librero J, Peiró S, Bernal-Delgado E, Rivas F, Martínez N, Sotoca R, Ridao M, Castaño E, Grupo Atlas VPM: Variaciones en las intervenciones de Cirugía General en el Sistema Nacional de Salud. Atlas Var Pract Med SNS 2006, 2:63-83.

30. Márquez-Calderón $\mathrm{S}$, Jiménez A, Perea-Milla E, Briones E, Aguayo E, Reina A, Aguado MJ, Rivas F, Rodríguez MM, Buzón ML, Grupo Atlas VPM: Variaciones en la hospitalización por problemas y procedimientos cardiovasculares en el Sistema Nacional de Salud. Atlas Var Pract Med SNS 2007, 4:151-173.

31. Serrano Aguilar P, López Bastida J, Ramallo Fariña Y, Cabrera Hernández JM, Perestelo Pérez L, Garcés Martín G, Nogales Hidalgo J, Vega Cid R, Rodríguez Santana I, García Huerte L, Heredero Robayna R, Mendoza Suárez N: Análisis coste - efectividad y resultados en salud en cirugía ortopédica de cadera y rodilla. Madrid: Plan Nacional para el SNS del MSC. Servicio de Evaluación del Servicio Canario de la Salud. 2007 [http://www2.gobiernodecanarias.org/sanidad/sescs/downloads/ inf_plan_calidad_pdf/2006_16.pdf], Informes de Evaluación de Tecnologías Sanitarias: SESCS № 2006/16.

32. Escobar A, Quintana JM, Bilbao A, Azkarate J, Güenaga Jl, Arenaza JC, Gutierrez LF: Effect of patient characteristics on reported outcomes after total knee replacement. Rheumatology (Oxford) 2007, 46:112-119.

33. Petterson SC, Raisis L, Bodenstab A, Snyder-Mackler L: Disease-specific gender differences among total knee arthroplasty candidates. J Bone Joint Surg Am 2007, 89:2327-2333.

34. Karlson EW, Daltroy $\mathrm{LH}$, Liang $\mathrm{MH}$, Eaton $\mathrm{HE}$, Katz JN: Gender differences in patient preferences may underlie differential utilization of elective surgery. Am J Med 1997, 102:524-530.

35. Arjona CR, Criado J, Sánchez L: Enfermedades crónicas y consumo de fármacos en mayores de 65 años. Medicina General 2002, 47:684-695.

36. Karlson EW, Mandl LA, Aweh GN, Sangha O, Liang MH, Grodstein F: Total hip replacement due to osteoarthritis: the importance of age, obesity, and other modifiable risk factors. Am J Med 2003, 114:93-98.

37. Hamel MB, Toth M, Legedza A, Rosen MP: Joint replacement surgery in elderly patients with severe osteoarthritis of the hip or knee: decision making, postoperative recovery, and clinical outcomes. Arch Intern Med 2008, 168:1430-1440

38. Naylor CD, Williams Jl: Primary hip and knee replacement surgery: Ontario criteria for case selection and surgical priority. Qual Health Care 1996, 5:20-30. 
39. García D, Ramón LR: Artrosis. In Guía de Actuación en Atención Primaria.. 2 edition. Edited by: Sociedad Española de Medicina Familiar y Comunitaria. Barcelona; 2002.

\section{Pre-publication history}

The pre-publication history for this paper can be accessed here: http://www.biomedcentral.com/1471-2474/11/249/prepub

doi:10.1186/1471-2474-11-249

Cite this article as: Cobos et al:: Variability of indication criteria in knee and hip replacement: an observational study. BMC Musculoskeletal Disorders 2010 11:249.

Submit your next manuscript to BioMed Central and take full advantage of:

- Convenient online submission

- Thorough peer review

- No space constraints or color figure charges

- Immediate publication on acceptance

- Inclusion in PubMed, CAS, Scopus and Google Scholar

- Research which is freely available for redistribution

Submit your manuscript at www.biomedcentral.com/submit
C Biomed Central 